\title{
7
}

\section{Income distribution in China}

\section{A macroeconometric approach}

\author{
Jordan Shan
}

Rapid economic growth in China since the 1980s has attracted worldwide attention, but there also has been increased awareness in the 1990s about China's possible regional income inequality, before and after the reform era. There is growing literature on this issue, and the bulk of the literature is concerned with an empirical question: is there regional income inequality in China since the 1980s and what are the sources of this dispersion?

This chapter adds to this empirical literature by applying a VAR model which uses VAR techniques such as innovation accounting and Granger causality to examine the causal linkage, where appropriate, between macro factors and income disparity in China. Other various interrelationships among economic variables of interest in a VAR system are also investigated. In particular, this study uses GDP data recently released by China's Statistical Bureau to investigate how macroeconomic activity and policy can impact on income inequality in China. There has been relatively little recent work on the impact of macroeconomic activity on the level of inequality in China. Previously, Raiser (1998), Chen and Fleisher (1996), Sun and Chai (1998) and Sun (1998) mentioned the roles played by foreign direct investment (FDI) and exports in income disparity but their focus was not on the relationship between macroeconomic activity and income equality in China. Other scholars, while examining the sources of income dispersion, have concentrated on micro factors of income inequality and their studies are generally descriptive rather than using more rigorous econometric techniques.

By using a VAR model this study examines the possible causal linkages between the macro factors and income dispersion in China in a dynamic context. It will also consider feedback between income inequality and several other macro variables. The rest of the chapter then presents a brief review of the literature, followed by an analysis of China's possible income dispersion 


\section{Income distribution in China}

using some standard statistical measures, such as coefficient variation and Gini coefficients. The econometric model used in this chapter is presented, including empirical results.

\section{A review}

This section provides a brief review of the literature on China's income inequality and includes an analysis of income disparity for the period 1955-98 using conventional statistical indicators.

Economists' views on the various impacts of disparity on growth are inconclusive. ${ }^{1}$ While it is not our intention in this chapter to judge whether there is a negative or positive relationship between economic growth and income disparity, it is important to note that this issue clearly has important policy implications, since income disparity exacerbates socio-political conflicts. Ultimately this will reduce growth (Benabou 1996 and Wu 1999). The Tiananmen incident in 1989 is an example of the importance and relevance of this disparity.

Therefore, we seek to address two questions: was there an income disparity in China before and after economic reform in the 1980s? If so, how do macroeconomic variables impact on this disparity?

This chapter concentrates on 1990s literature on Chinese income disparity. Table 7.1 presents some findings from previous studies. It is apparent that these economists were mainly concerned with whether or not there is income disparity or convergence in China. Their conclusions were mixed. While some economists presented evidence of reduced income disparity between the 1950s and 1990s others argued to the contrary (see for example, World Bank 1997; Wu 1999; Raiser 1998; Chen et al. 1996).

Some economists have looked into the causes of income inequality in China (for example, Hussain et al. 1994; Zhao and Li 1997; Khan and Riskin 1998; Tsui 1998). However, they all focused on micro variables such as non-farming and rental income, rural industrialisation levels, productivity and efficiency differences and urban-rural income gaps, and so on. The methodology used was index decomposition or other descriptive index numbers. No strong econometric method has been used in previous studies.

It is important to note that, as argued by Balke and Slottje (1994), macro variables could have an important impact on income disparity. Macroeconomic policy (such as fiscal spending, money supply and interest rates) and other macroeconomic variables (such as inflation, exports and inflation levels) will impact on income disparity. According to Balke and Slottje (1994), the role of government as a mechanism for redistribution and hence, the development of public policy, will inevitably influence the level of income inequality because 


\section{Dilemmas of China's Growth in the Twenty-first Century}

of the impact of redistribution on regional economies. For instance, money supply and fiscal spending could have strong countercyclical effects. They may affect labour supply and GDP growth differently according to each region and hence have different effects on income disparity. This is particularly relevant in the Chinese case where the impact of money supply and fiscal policy on output and labour supply have been considerably different before and after the opendoor policy. Similarly, macroeconomic variables such as exports and population and unemployment growth would also cause income disparity. In fact, Balke and Slottje (1994) and Blank and Blinder (1986) proposed that income inequality is a function of unemployment, inflation, fiscal spending and money supply. Other economists such as Blank (1989) also discussed the importance of including macroeconomic measures as sources of income disparity.

While these economists were primarily concerned with the cases of industrialised economies, their work sheds light on the debate regarding China. It is possible, for instance, that the Chinese fiscal system could have different redistributive effects on regional development and subsequently on income disparity in China. Without a doubt, fiscal spending is an important input in Chinese regional development, even after the de-centralisation of its fiscal system. Note that this chapter does not intend to investigate specific redistributive programs or the details of fiscal reform in China. We are interested in how overall fiscal spending influences the Chinese economy and how various macroeconomic factors interact to affect income dispersion, and vice versa. Macroeconomic variables such as FDI and exports could also contribute to income inequality in China. It is well know that FDI and exports have played an important role in Chinese economic development (Shan and Sun 1998; Sun and Chai 1998), but there are clear differences in FDI inflows and export performances in different Chinese provinces (see Sun 1998; Sun and Chai 1998). Thus, macroeconomic activities may have varying impacts on income disparity in China.

It is important to examine the relationship between income disparity, macroeconomic policy and macroeconomic activity in a dynamic way-that is, to look at how this relationship may have changed over time and how each macroeconomic activity influences income disparity in China. We also investigate fiscal spending dispersion and other dispersions such as money supply and inflation, and the relative contribution of these dispersions to income inequality in China between 1955-98.

\section{Increasing income disparity in the 1990s}

To measure income dispersion, we use the Gini coefficient, coefficient variation and Theil's Index. ${ }^{2}$ Figure 7.1 plots these measurements between 1955-98. It 


\section{Income distribution in China}

shows clearly that there was an increase in income inequality in China in the late 1990s. All three measures show a similar pattern.

We also used 20 percentile and 80 percentile values, which measure the income levels for those income groups lower than 20 per cent and higher than 20 per cent within the population (Figure 7.2). Again there is evidence of income disparity in China after the reform policy, as the chart shows an increasing gap between mean income levels lower and higher than 20 per cent. This result supports the findings of Chen (1995) and Tsui (1998) but contrasts with the findings of Wu (1999) and Jian et al. (1996).

During the 1990s there was not only an increase in Chinese income dispersion but also major changes in macroeconomic performances and policies. During this decade, the opening of the Chinese financial system brought about a more market-orientated monetary policy. Similarly, China adopted a more expansionary fiscal policy combined with swifter decentralisation of its fiscal structure. The inflation rate fell in the late 1990s after high rates in the late 1980 s and early 1990s. However, it had different lag effects in different regions. At the same time, the so-called reform of state-owned enterprises began in the late 1990s and has further increased the unemployment level in China. To what extent do these macroeconomic variables explain the increase in income disparity in China?

\section{The model}

We use a VAR model to examine the relationship between income disparity and macroeconomic activity in China. A VAR model is attractive because it need not impose any theoretical restrictions on the dynamic behaviour of the variables in the system and will let data speak with regard to the issue we wish to investigate. VAR analysis is common in the estimation and inference of macroeconomic relationships, despite its drawbacks in certain areas. ${ }^{3} \mathrm{~A}$ VAR model is useful if there is no prior information and economic theories do not suggest a specific model. It is worth noting that a consensus is ineffective with a well-defined static theory of income distribution, let alone in terms of a dynamic theory.

According to Gujarati (1995:750) the centrepiece of VAR is innovation accounting. As mentioned earlier, innovation accounting includes both variance decomposition and impulse response function. Variance decomposition may be thought of in the following way. Suppose we wanted to use estimated VAR to forecast levels of income inequality in the future. The variance decomposition tells us how much of the forecast error variance in income inequality in each future forecast error period would be due to an innovation in the variable in question.

Furthermore, one has to keep in mind that there are possible feedbacks among several of the variables of interest. It is important to consider the 


\section{Dilemmas of China's Growth in the Twenty-first Century}

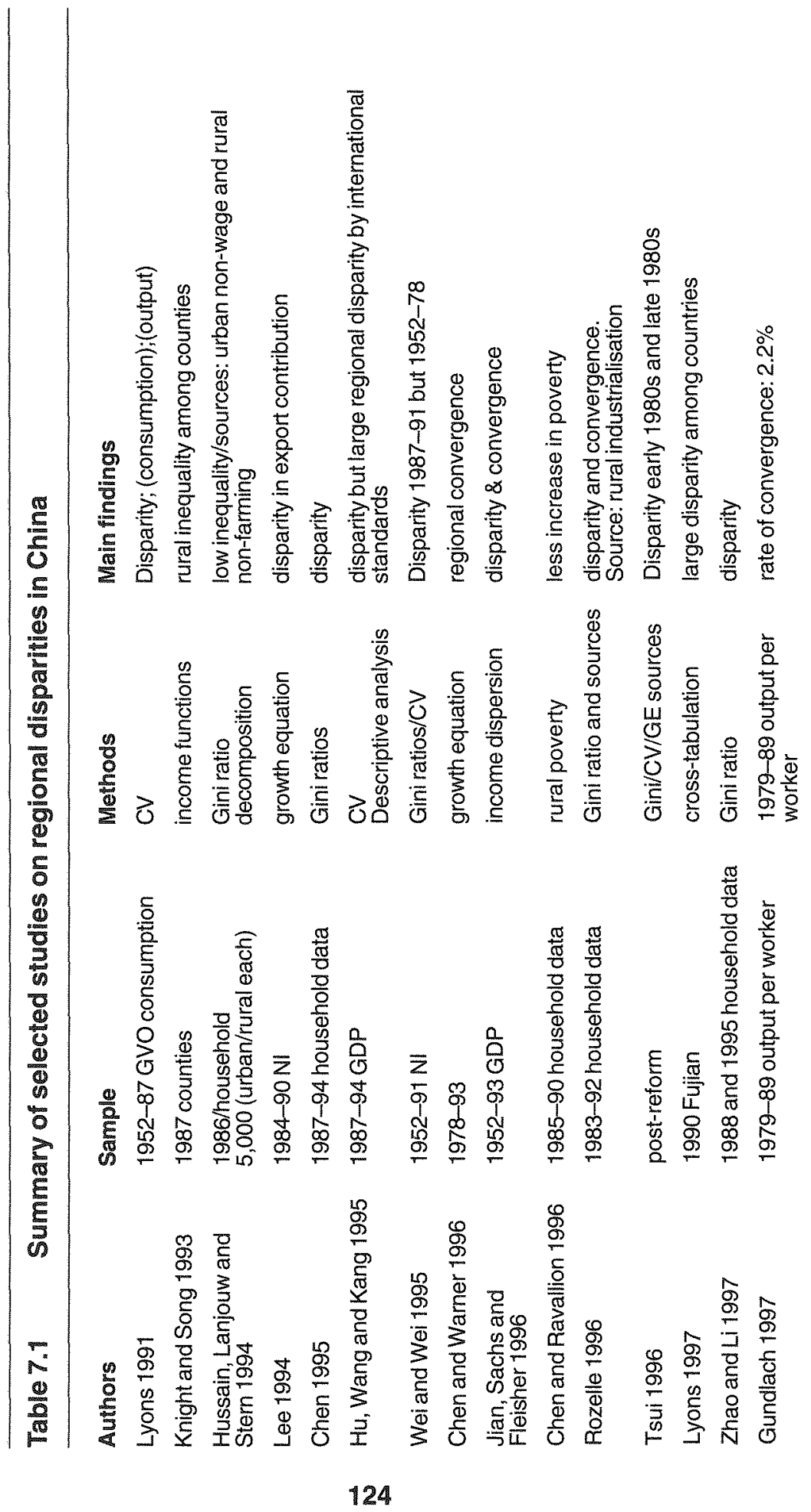


Income distribution in China

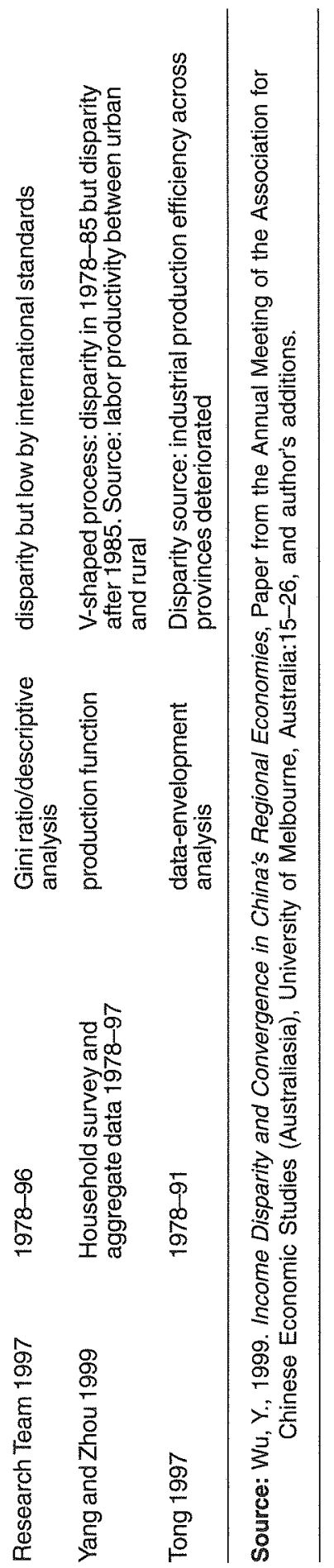


Dilemmas of China's Growth in the Twenty-first Century

\section{Figure 7.1 Income disparity in China: index numbers}

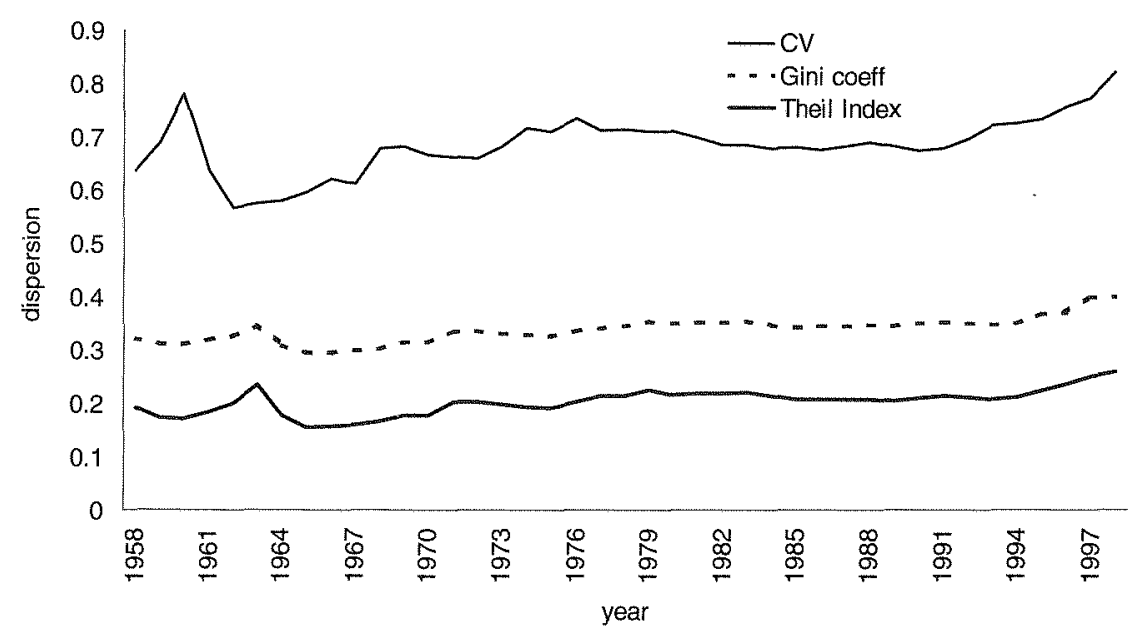

Figure 7.2 Income dispersion in China: mean and percentile values

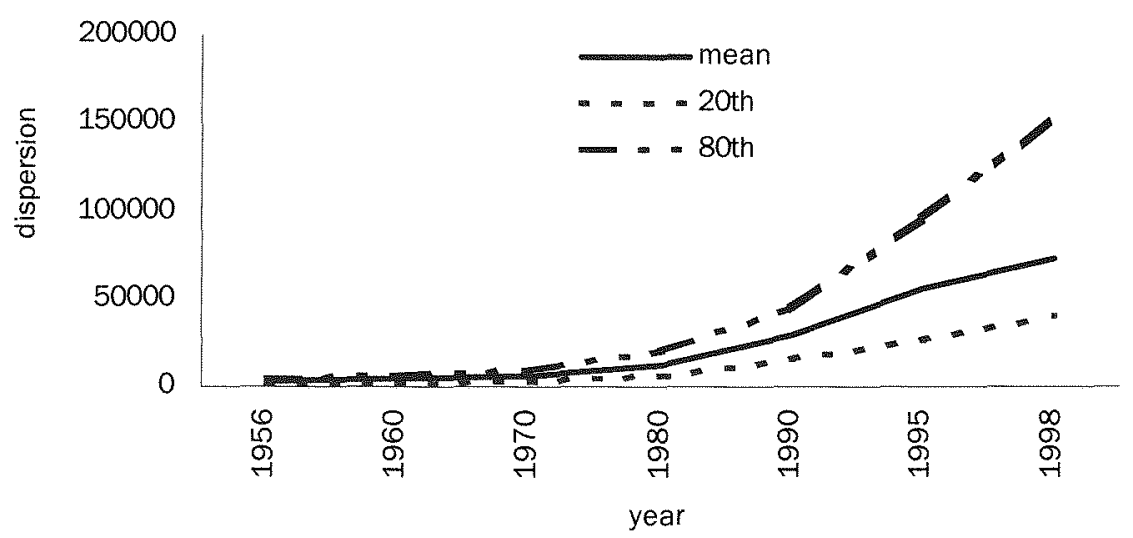




\section{Income distribution in China}

endogenous nature of a model like this one or it may be subject to a simultaneity bias. The use of a VAR model has been proven to generate more reliable estimates in an endogenous context (Gujarati 1995).

It must be acknowledged that the use of a VAR model is considered to be controversial within econometric literature. Concern is mainly focused on the choice of the lag length, the problem of being a-theoretic (it uses less prior information) and the difficulty of ensuring joint stationarity for all variables included in the VAR. If handled with care, however, 'they can be useful tools to examine the relationships among economic variables in a dynamic context' (Enders 1995:312).

We address these concerns by using AIC and SC to aid in choosing the lag length and, more importantly, to estimate the VAR with several lag structures to ensure that the results are robust. ${ }^{4}$ As argued earlier, although the VAR may be considered a-theoretic, it is appropriate in a case in which no prior information or theories can be utilised. Furthermore, as Gujarati (1995:74950) argues, a VAR model makes estimations simpler and the OLS estimation method can be used, provided all variables in the VAR are integrated in the same order.

The VAR used is

$$
\begin{aligned}
& V_{t}=A_{0}+\sum_{i=1}^{k} A_{i} V_{t-i}+\varepsilon_{t} \\
& \text { where } V_{t}=\left(C V_{t}, F P_{t}, M S_{t}, E X P O R T S_{t}, F D I_{t}, C P I_{t}, U N_{t}\right)
\end{aligned}
$$$$
\varepsilon_{t}=\left(\varepsilon_{g d p_{t}}, \varepsilon_{f p_{t}}, \varepsilon_{m s}, \varepsilon_{\text {export }}, \varepsilon_{f d i}, \varepsilon_{C P I_{t}}, \varepsilon_{\text {un }}\right)
$$

and $A_{1}$ to $A_{k}$ are seven-by-seven matrices of coefficients; $A_{0}$ is an identity matrix; $C V$ is the coefficient variation of per capita GDP of China; MS is money supply (M1); FP is fiscal spending; EX is exports; CPI is consumer price index (previous year $=100$ ); FDI is total foreign direct investment and foreign loans actually utilised at the end of each year; UN is unemployment represented by the number of unemployed people in an urban area at the end of each year. ${ }^{5}$

\section{The data}

The VAR model is estimated using annual data in real terms (1985 prices) over the period 1955-98. In order to ensure stationarity of the data, all variables such as money supply (money), FDI, unemployment (UN), inflation level (CPI), exports (EX) and fiscal spending (FP) are in first differences of logarithms (growth rates).

Data is sourced from The China Statistical Yearbook, Market Statistical Yearbook of China, Historical Data of GDP Statistics in China, Fifty Years of New China, and China Trade Union Statistics Yearbook, as detailed in Appendix 7.1. 


\section{Dilemmas of China's Growth in the Twenty-first Century}

\section{Empirical results}

According to Enders (1995), the forecast error variance decomposition allows inference over the proportion of the movement in a time series, due to its own shocks versus shocks to other variables in the system. This breaks down the variance of the forecast error for each variable into components that can be attributed to each of the endogenous variables. On the other hand, impulse response function analysis traces the time path of various shocks on the variables contained in the VAR system. In other words, this approach determines how each endogenous variable responds over time to a shock in that variable and in every other endogenous variable. It traces the responses of the endogenous variables to such shocks. These two methods, which when combined are called innovation accounting, allow an intuitive insight into the dynamic relationships among the economic variables of interest in the VAR.

We can therefore use the variance decomposition method to break down the variance of the forecast error for the income dispersion, measured by coefficient variation (CV) into components that can be attributed to each of the endogenous variables. That is, money supply (money), FDI, unemployment (UN), inflation level (CPI), exports (EX), and fiscal spending (FP) in the VAR. If one variable (for instance, FDI) explains more in the variance of the forecast error for $\mathrm{CV}$, then we would establish the hypothesis that FDI is the major source of income disparity in China.

At the same time, we can use the impulse response function to trace how the $\mathrm{CV}$ variable responds over time to a shock in another variable, and compared to its responses, to every other endogenous variable in the VAR. If the impulse response function shows a stronger and longer response of $\mathrm{CV}$ to a shock in FDI (for example), then we can establish that FDI is the most important source of income inequality in China.

The forecast error variance decomposition of unrestricted VAR (3) models consisting of the above variables were estimated using the Choleski decomposition method over a thirty-year forecast horizon (Table 7.2). ${ }^{6}$

As one would expect, innovations in income dispersion are explained by the preponderance of its own past values (26-30 per cent) over the different forecast horizons. It is followed by unemployment and fiscal spending (each around 25 per cent), exports and FDI (each around 10 per cent), and finally by inflation and money supply (each around 2 per cent).

In combining these results, we make further findings. Innovations in unemployment and fiscal spending together account for over 50 per cent of the forecast error variance at the various forecast horizons. The external factors (for instance exports and FDI) together account for around 20 per cent, while the monetary forces (for instance money supply and inflation level) together were below 5 per cent of the forecast error variance. 


\section{Income distribution in China}

These results suggest that unemployment and fiscal spending are the most important forces in explaining the variations in China's income disparity between 1955-98. This indicates that fiscal policy plays an important role in the Chinese economy, while unemployment/population growth is a major constraint on income growth in China.

On the other hand, the monetary forces (that is, money supply and inflation level) play a less significant role in income inequality in China. This suggests that until the 1990s monetary policy was an unimportant and ineffective policy tool in promoting China's income growth. This is due perhaps to China's underdeveloped financial system, something that has gradually changed since the 1990s. The finding that fiscal spending and unemployment are more important than monetary factors is consistent with literature on income dispersion for industrialised economies (Balke and Slottje 1994; Blank 1989).

However, exports and FDI are not the most important elements influencing income disparity in China. This finding contradicts Sun and Chai (1998), and others who argue that FDI and exports can have different effects on regional development in China and hence, have different impacts on income distribution.

As a final note concerning variance decomposition results, one should pay attention to the values of the components of forecast errors over the entire forecast horizon. The results in Table 7.2 suggest that the proportion of each component (of forecast error variance) remain the same. As mentioned earlier, they are also robust to different lag structures. ${ }^{7}$

\section{Empirical results based on dispersion variables}

To investigate the source of income inequality further, we also used the dispersion variable for all variables discussed earlier. We used coefficient variation for money

\section{Table 7.2 Variance decomposition for income dispersion (per cent)}

\begin{tabular}{|c|c|c|c|c|c|c|c|}
\hline \multirow[b]{2}{*}{ Horizon } & \multirow[b]{2}{*}{$\mathrm{CV}$} & \multicolumn{3}{|c|}{ Forecast error attributed t } & \multirow{2}{*}{${ }^{\circ}$ Inflation } & \multirow[b]{2}{*}{ Unemployment } & \multirow[b]{2}{*}{ Exports } \\
\hline & & FDI & Fiscal & Money & & & \\
\hline 1 & 41.4 & 7.8 & 21.4 & 0.9 & 1.4 & 21.5 & 5.6 \\
\hline 2 & 30.0 & 7.0 & 23.6 & 1.8 & 1.4 & 27.5 & 8.7 \\
\hline$\overline{3}$ & 27.4 & 7.8 & 24.6 & 1.7 & 1.3 & 27.2 & 10.0 \\
\hline 4 & 26.4 & 8.5 & 24.8 & 1.9 & 1.5 & 26.3 & 10.5 \\
\hline 5 & 26.2 & 9.1 & 24.5 & 2.0 & 2.0 & 25.9 & 10.3 \\
\hline 6 & 26.1 & 9.1 & 24.4 & 2.0 & 2.1 & 25.8 & 10.5 \\
\hline 7 & 26.0 & 9.1 & 24.4 & 2.0 & 2.1 & 25.8 & 10.7 \\
\hline 8 & 26.0 & 9.1 & 24.3 & 2.0 & 2.1 & 25.8 & 10.6 \\
\hline 9 & 26.0 & 9.2 & 24.3 & 2.0 & 2.1 & 25.8 & 10.6 \\
\hline 10 & 25.9 & 9.2 & 24.3 & 2.0 & 2.1 & 25.7 & 10.7 \\
\hline 15 & 26.3 & 9.1 & 23.9 & 2.1 & 2.5 & 25.3 & 10.8 \\
\hline 20 & 25.0 & 8.7 & 22.9 & 2.0 & 4.4 & 24.6 & 12.4 \\
\hline 30 & 22.0 & 8.5 & 22.1 & 1.9 & 6.2 & 24.3 & 14.9 \\
\hline
\end{tabular}




\section{Dilemmas of China's Growth in the Twenty-first Century}

supply, unemployment, inflation level, exports, FDI and fiscal spending. This means that each variable measured the dispersion of that variable over different provinces in China so that we could find the dispersion variable and the extent to which it influenced income dispersion (Table 7.3). ${ }^{8}$

These results confirm the findings reported in Table 7.2. That is, the dispersions in fiscal spending and unemployment explain most of the forecast error variance for overall income dispersion in China. Table 7.3 shows that dispersions in unemployment and fiscal spending together again account for over 50 per cent of the forecast error variance at the various forecast horizons, followed by the external variables (exports and FDI). Finally, the combined monetary forces (money supply and inflation level) were below 5 per cent of the forecast error variance.

This suggests that the macroeconomic reasons for China's income disparity over the 1955-98 period are dispersions in unemployment and fiscal spending among different provinces. Again this indicates that fiscal policy plays an important role in the Chinese economy, and that unemployment/population growth is a major constraint on income growth in China. On the other hand, the monetary forces (money supply and inflation level) play a less significant role in income inequality in China.

\section{Impulse response function}

We now proceed to impulse response function analysis. As suggested above, a graphic illustration of the impulse response function can provide an intuitive insight into the dynamic relationships that exist, because it presents the response of one variable to an unexpected shock in another over a certain time horizon (Figure 7.3).

Figure 7.3 illustrates the response of income dispersion (CV) to a shock in six other variables (money supply, FDI, inflation, fiscal spending, exports and unemployment). The response of income disparity (CV) to fiscal spending and unemployment has been most responsive (3-4 per cent changes for a 1 per cent shock in six other variables). This result confirms our earlier finding that both unemployment and fiscal finding are the two most influential factors in China's income dispersion.

Exports were found to be the third most important variable that explaining variations in income disparity in China (around 3 per cent change for a 1 per cent change in the six other variables). Figure 7.3 shows that FDI, money supply and inflation level have a much smaller effect on the income dispersion variable (CV) compared to unemployment and fiscal spending. 


\section{Income distribution in China}

Finally, the response of CV to all other variables shows that $\mathrm{CV}$ reverts back to its original levels over about a seven-year time horizon.

\section{Granger causallity test}

Another important aspect of VAR analysis is the Granger causality test. It states that $\mathrm{X}$ is said to Granger cause $\mathrm{Y}$ if past values of $\mathrm{X}$ can predict or precede the changes in $Y$. This study uses a Granger no-causality test developed by Toda and Yamamoto and extended and interpreted by Zapata and Rambaldi (1997).

We wish to find out if there is a Granger-type causal relationship between macroeconomic activities, macroeconomic policy and income inequality in China.

The results, reported in Table 7.4, indicate that there is Granger causality from unemployment and fiscal spending to income dispersion (both are significant at 95 per cent). However, the causal relationship between other variables and income disparity are weak (marginal at about 85 per cent). This finding is consistent with findings from the innovation accounting analysis.

Finally, the opposite causality (from income dispersion to macro variables) was not found or is only marginally significant. It suggests that innovations in income disparity do not have significant feedbacks on other macro variables in the VAR system. This was an interesting finding since there is also a debate as to whether or not income inequality hinders economic development. In passing, our findings do not support the view that income disparity will prevent further economic growth (Clarke 1995).

\section{Table 7.3 Variance decomposition for income dispersion (per cent)}

\begin{tabular}{crrrrrrr} 
Horizon & CV & FDI & Fiscal & $\begin{array}{c}\text { Focast error attributed to } \\
\text { Money }\end{array}$ & inflation Unemployment & Exports \\
1 & 40.3 & 8.9 & 21.9 & 0.7 & 1.7 & 22.0 & 5.1 \\
2 & 28.9 & 8.1 & 24.1 & 1.6 & 1.7 & 28.0 & 8.2 \\
3 & 26.2 & 8.9 & 25.1 & 1.5 & 1.6 & 27.7 & 9.5 \\
4 & 25.3 & 9.6 & 25.3 & 1.7 & 1.8 & 26.8 & 10.0 \\
5 & 25.1 & 10.2 & 25.0 & 1.8 & 2.3 & 26.4 & 9.8 \\
6 & 25.0 & 10.2 & 24.9 & 1.8 & 2.4 & 26.3 & 10.0 \\
7 & 24.9 & 10.1 & 24.9 & 1.4 & 2.4 & 26.4 & 10.2 \\
8 & 24.9 & 10.2 & 24.8 & 1.8 & 2.3 & 26.3 & 10.1 \\
9 & 24.9 & 10.3 & 24.8 & 1.7 & 2.5 & 26.1 & 10.2 \\
10 & 24.8 & 10.3 & 24.8 & 1.8 & 2.4 & 26.2 & 10.2 \\
15 & 25.2 & 10.2 & 24.4 & 1.9 & 2.8 & 25.8 & 10.3 \\
20 & 23.9 & 9.8 & 23.4 & 1.8 & 4.7 & 25.1 & 11.9 \\
30 & 20.9 & 9.6 & 22.6 & 1.7 & 6.5 & 24.8 & 14.4 \\
\hline
\end{tabular}

Note: All variables are in coefficient variation form. 


\section{Dilemmas of China's Growth in the Twenty-first Century}

\section{Conclusion}

This study has investigated an issue that has drawn worldwide attention since the 1980s. How did macroeconomic activity and macroeconomic policy attribute to widening income disparity in China? This is an important question given that income inequality in China has increased in the 1990s, alongside vigorous economic growth. Unlike other scholars who have looked for micro factors, we have attempted to find an answer to this question by examining macro factors, such as inflation and unemployment, and macroeconomic policy such as fiscal spending and money supply.

Using a VAR approach, we have put China's income dispersion and other macro variables in a dynamic context to examine how they have interacted over a long time horizon. We found that unemployment and the dispersion of fiscal spending across different provinces played a prominent role in widening income inequality in China. On the other hand, monetary factors had a less significant role.

This finding provides strong empirical evidence for the view that macroeconomic forces have an important effect on income distribution, which is also consistent with findings based on industrialised economies (Balke and Slottje 1994). Both economists and policymakers should not lose sight of this fact.

A strong policy implication arising from this study is that a sound macroeconomic environment is crucial to income equality in China.

It is worth mentioning that the results reported here are not a substitute for, but a complement to, traditional microeconomic labour economics regarding income distribution. Future research might consider an approach that integrates

\section{Figure 7.3 Responses of CV to other variables}

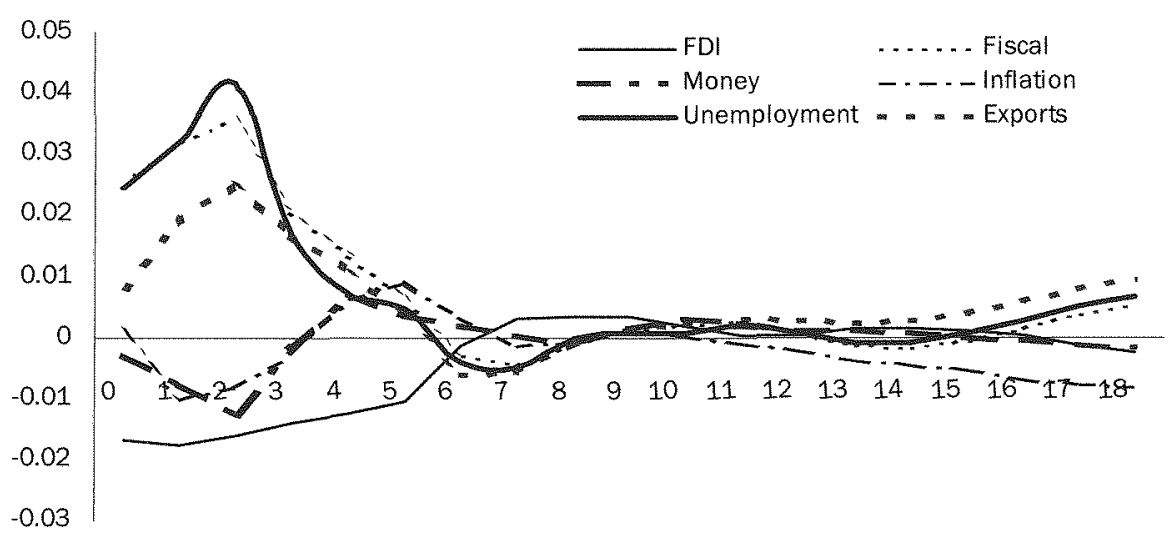




\section{Income distribution in China}

\section{Table 7.4 Income disparity and macro variables}

\section{Causality pairs}

$\mathrm{CV}$, unemployment

CV, fiscal spending

$\mathrm{CV}$, money

$\mathrm{CV}, \mathrm{CPI}$

$\mathrm{CV}$, exports

$\mathrm{CV}, \mathrm{FDI}$

\section{p-values for both directions of the causality}

0.085 vs 0.001

0.190 vs 0.006

0.302 vs 0.199

0.178 vs 0.098

0.201 vs 0.090

0.101 vs 0.094

Note: The VAR order(s) for all causalities in this table are in optimal lag structures and was determined by $\mathrm{AIC}$ and $\mathrm{SC}$. Variable definitions are explained in the text.

these two literatures and uses more rigorous econometric methodology and strong economic theory.

\section{Appendix 7.1}

The VAR model is estimated using annual data in real terms (1985 prices) over the period 1955-98. The data coverage for each series is cited from China Statistical Yearbook 1998, 'Explanatory Notes of Indicators', CD-Rom, Beijing. All data are in annual growth rates.

The data sources are as follows.

- GDP's CV: China Statistical Bureau, China's GDP Data 1952-95, Dongbei University of Economics and Finance Press, Dalian.

- The data for 1997 and 1998 are from China Statistical Bureau, 1999. China Statistical Yearbook, Beijing. The formula for CV is:

- Fiscal spending: China Statistical Bureau, 1998. Market Statistical Yearbook of China, Beijing:15. Data for 1998 was from China Statistical Bureau, 1999. China Statistical Yearbook, Beijing.

- Money supply: China Statistical Bureau, 1998. Market Statistical Yearbook of China, Beijing:22. Data for 1998 was from China Statistical Bureau, 1999. China Statistical Yearbook, Beijing.

- Inflation is CPI (previous year = 100). China Statistical Bureau, 1998. Market Statistical Yearbook of China, Beijing:273. Data for 1998 was from China Statistical Bureau, 1999. China Statistical Yearbook, Beijing.

- Exports: China Statistical Bureau, 1998. Market Statistical Yearbook of China, Beijing:328. Data for 1998 was from China Statistical Bureau, 1999. China Statistical Yearbook, Beijing.

- Unemployment: China Statistical Bureau, 1990. China Statistical Yearbook, Beijing:130; China Statistical Bureau, 1999. China Trade Union Statistics Yearbook, Beijing:60. 


\section{Dilemmas of China's Growth in the Twenty-first Century}

- FDI: includes all foreign capital (both FDI and foreign loans) which was the amount actually used.

The data for local provinces are from 18 provincial statistical yearbooks, including Tinjin, Beijing, Shanghai, Shandong, Hebei, Jilin, Jiangxi, Heilongjiang, Guizhou, Henan, Anhui, Guangdong, Shanxi, Liaoning, Jiangsu, Zhejiang, Hubei, Sichuan and NingXia. Due to the lack of data over the same range of variables, this sample provides a good approximation.

\section{Notes}

1 See Benabou (1996) for a comprehensive review.

2 The formulae for these indices are: coefficient variation $=1 / 2 \Sigma(Y-Y)^{2} / \mathrm{n} / \mathrm{Y}$.

Theil Index $=\sum Y \log \left(Y_{i} / Y\right) / n Y$.

Gini coefficient $=\sum \sum 1 / 2\left(Y_{i}-Y_{i}\right)^{2} / 2 n^{2} / Y$.

where $Y_{i}$ is per capita income, $Y$ is average per capita income and $n$ is the sample size.

3 See Gujarati (1995) for a detailed discussion of advantages and disadvantages of using a VAR for macroeconomic analysis.

4 Our VAR estimation under different lag structures indicates no significantly different results and hence we present the results from VAR (3), which is an optimal lag length according to AIC and SC.

5 The data prior to 1982 was estimated by using the formula stated in The China Statistical Yearbook, 1999. The unemployment rate is 100 per cent urban unemployed persons/ non-rural population.

6 Optimal lag length was chosen according to AIC and SC.

7 Results for different lag structures are not reported but are available upon request from the author.

8 Due to the lack of data over the same range of variables, only 19 provinces were used in this study (Tinjin, Beijing, Shanghai, Shandong, Hebei, Jilin, Jiangxi, Heilongjiang, Guizhou, Henan, Anhui, Guangdong, Shanxi, Liaoning, Jiangsu, Zhejiang, Hubei, Sichuan and NingXia). But it is conceivable that this sample provides a good approximation. 